\title{
Use of Compressive Reactor for Associated Petroleum Gas Processing
}

\author{
B. S. Ezdin, A. A. Nikiforov, V. E. Fedorov, A. E. Zarvin, S. A. Konovalov, V. V. Kalyada, I. V. Mishchenko \\ Department of Applied Physics, Novosibirsk State University, Novosibirsk, Russia \\ Email: sintez-t@ngs.ru
}

Received 2012

\begin{abstract}
The possibility of using of a pair of compression piston - cylinder with the unique performance features for the conversion of hydrocarbons are discusses. The experimental facility enables working in the pressure range that would be unattainable in diesel engines. The necessary degree of compression is managed and maintained by the computer system with a feedback.
\end{abstract}

Keywords: Oxidation; Natural Gas; Assotiatied Gas; Chemical Compression Reactor

\section{Introduction}

For the past two decades, researchers in many countries try to invent a direct method of natural and petroleum gas conversion into heavy hydrocarbons bypassing a gas synthesis stage. The idea is to create a compact high-performance mobile processing unit to use it directly in the oil processing industry.

\section{Experiment}

Methods were developed to produce the synthesis gas and other products of associated gas from the natural gas in the chemical compression reactor - diesel engine for example [1,2].

Research team headed by A. Nikiforov, has worked out a method of a surface TECH-oxidation [3]. The covering resistant to the thermal cycling, is highly resistant to abrasion and heat. The coefficient of friction between the two coverings does not exceed $5 * 10^{-2}$. Surfaces in the reaction zone can withstand operating temperatures of more than $2000 \mathrm{~K}$. One of the perspective applications of this innovation is to use a pair of compression "piston - cylinder" with the unique performance features for the conversion of hydrocarbons.

We have developed an original compression reactor to produce synthesis gas and for the controlled oxidation of associated gas to ethers and peroxy compounds. The reactor consists of piston and cylinder that are cooled. They are driven by a crank mechanism with tension rod. This mechanism provides a translational-rotational motion of the cylinder without lateral forces on the piston. The reactor has a system of measuring pressure in the reaction volume in real time. The construction provides the controlled regulation mechanisms of the cylinder upper dead point. These mechanisms have a response time of 0.1 seconds and an accuracy of 10 microns. Other mechanisms feed the reacting mixture in the reaction volume with a minimum response time of $0.5 \mathrm{~ms}$. There is a system cooling the piston and the cylinder of the reactor in order to maintain an optimum gap between them. The working volume of the reactor is 0.1 to 0.6 liters. The optimal frequency of reactor operation is up to $10 \mathrm{~Hz}$. The reactor is equipped with systems collecting reaction products, systems separating raw materials that didn't react to bring them back to the reactor entrance. Hardwaresoftware system supporting the reactor provides on-line data and enables to manage the reactor mechanisms in order to optimize and to increase the reaction outcome percentage.

The set includes the electromechanical reactor startup system and the system collecting the excess energy released during the chemical reactions. Without lubrication as the surface to surface friction coefficient is low, there is no influence of lubricating materials during the process of chemical reactions inside of the reactor. The reactor construction enables to have a pressure above $100 \mathrm{~atm}$ in the chamber. This pressure in its turn enables a wide range of chemical reactions. The pressure control mechanism inside of the reaction volume provides information about the processes taking place during the reaction. The appearance of the reactor, as well as remote control systems is shown in the photographs (Figures 1-3).

We have carried out a series of primary research of the process of the controlled chemical reaction in the chamber up to the stage of the gas mixture oxidation and generation of ether and peroxide compounds.

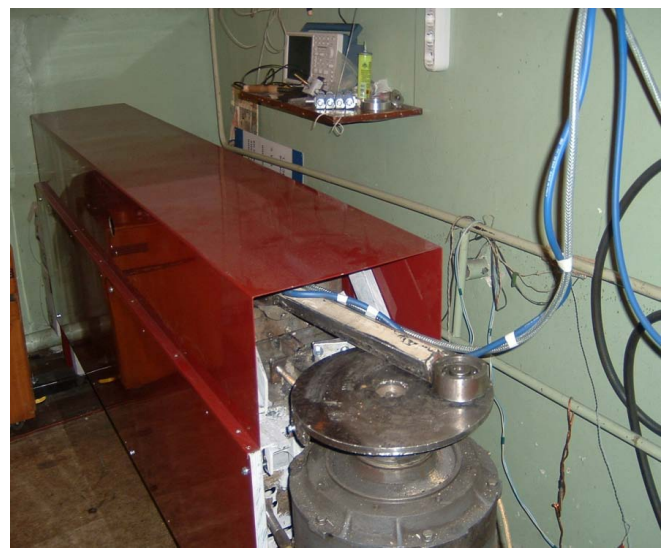

Figure 1. The appearance of the reactor. In the foreground is the engine with a crank mechanism and tension rods. 


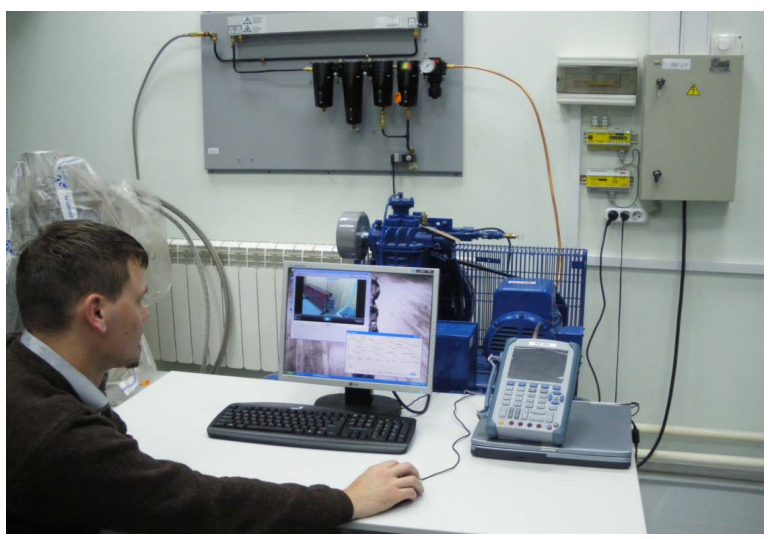

Figure 2. The process remote control system..

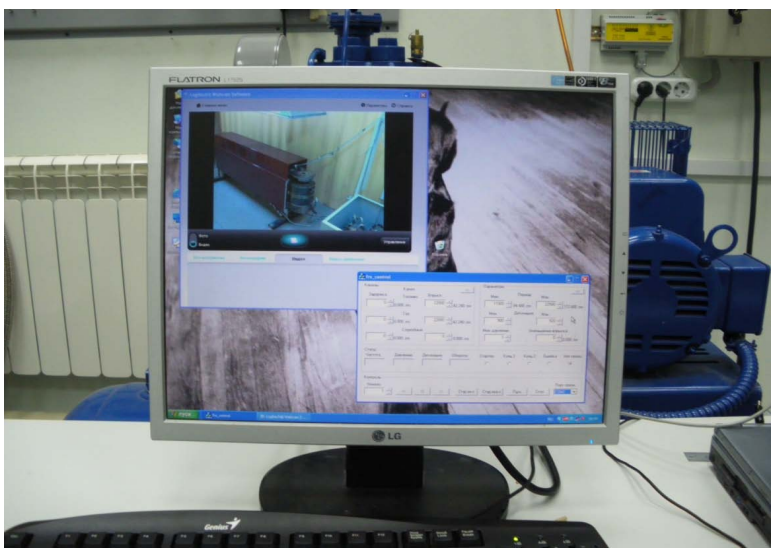

Figure 3. All the information about the process is transferred to the operator's monitor.

Pentane was used as a raw material. Main interest is the start up of a chemical reaction in methane and methane mixture to higher hydrocarbons. The calculated curve of methane and methane mixture oxidation indicates the necessity to maintain the reacting mixture pressure at the level of $90 \mathrm{~atm}$. According to evaluations the pressure increase transfers the reacting system from the mode of chain ignition to the quasistationary mode of branched-chain oxidation, providing a high reaction rate at relatively low temperatures. It also minimizes the influence of heterogeneous processes resulting in the formation of deep oxidation products.

The experimental facility enables working in the pressure range that would be unattainable in diesel engines. The necessary degree of compression is managed and maintained by the computer system with a feedback. That would be unavailable in the alternative systems.

Sampling from the reaction volume was made through a special channel drainage products from the compression chamber. The analyzed sample was collected in an evacuated container and transported to the analyzer. The analysis was performed using the branching and the identification by GCMS-QP2010 Plus the company Shimadzu (Japan). Chromatographic column used Supel Q-PLOT $30 \mathrm{~m}$ long and $0.32 \mathrm{~mm}$ inner diameter. Search for sample components was performed by treating the chromatograms of the total ion current. Identification of the observed peaks in the chromatogram was performed by match- ing the observed mass spectra and mass spectra of NIST electronic library.

The result of analysis of such samples at a compression pressure of 60 atm shown in Table 1, and a fragment of the chromatogram - in Figure 4. As expected, in mixtures with high oxygen concentration was achieved complete combustion of the reagents with the formation of the final products: carbon dioxide and water.

We expect that the regime of mixtures with low oxygen content (up to $7 \%$ ) would work in a chemical reactor mode conversion of hydrocarbon and / or partial oxidation. The result of the first tests setting in this mode are shown in Table 2, a fragment of the chromatogram - in Figure 5. The analysis revealed the presence of complex hydrocarbons.

Thus, this technological installation can be used as a free piston engines with a low coefficient of friction, as well as to achieve the parameters corresponding to the nonequilibrium processes of synthesis of hydrocarbons. At present, successive iterations are working to raise the pressure in the reaction volume in order to expand the experimentally accessible region to study the effect of pressure on the processes of synthesis and partial oxidation.

Table 1. Analysis of the composition of a sample number 12/05.

\begin{tabular}{|c|c|c|c|}
\hline $\begin{array}{l}\text { Number of } \\
\text { the peak }\end{array}$ & $\begin{array}{c}\text { Retention time, } \\
\text { minutes. мин }\end{array}$ & Peak area,\% & $\begin{array}{l}\text { The substance } \\
\text { (chemical formula) }\end{array}$ \\
\hline 1 & 1.266 & 58,48 & $\mathrm{~N}_{2}$ and $\mathrm{CO}$ in the sum \\
\hline 2 & 1.266 & 10,04 & $\mathrm{O}_{2}$ \\
\hline 3 & 1,266 & 1,92 & $\mathrm{Ar}$ \\
\hline 4 & 1.266 & 4,81 & $\mathrm{CH}_{4}$ \\
\hline 5 & 1.349 & 3,10 & $\mathrm{CO}_{2}$ \\
\hline 6 & 1.466 & 1,91 & $\mathrm{C}_{2} \mathrm{H}_{4}$ \\
\hline 7 & 1.571 & 1,72 & $\mathrm{C}_{2} \mathrm{H}_{6}$ \\
\hline 8 & 1.930 & 1,1 & $\mathrm{H}_{2} \mathrm{O}$ \\
\hline 9 & 3.253 & 0,96 & Propene $\mathrm{C}_{3} \mathrm{H}_{6}$ \\
\hline 10 & 3.453 & 12,57 & Propane $\mathrm{C}_{3} \mathrm{H}_{8}$ \\
\hline 11 & 6.573 & 0,11 & Ethylene oxide $\mathrm{C}_{2} \mathrm{H}_{4} \mathrm{O}$ \\
\hline 12 & 7.984 & 0,22 & Isobutane $\mathrm{C}_{4} \mathrm{H}_{10}$ \\
\hline 13 & 8.449 & 1,04 & 2-Butene,(Z) $\mathrm{C}_{4} \mathrm{H}_{8}$ \\
\hline 14 & 8.753 & 1,65 & n-Butane, $\mathrm{C}_{4} \mathrm{H}_{10}$ \\
\hline 15 & 8.965 & 0,25 & 2-Butene $\quad \mathrm{C}_{4} \mathrm{H}_{8}$ \\
\hline 16 & 9.117 & 0,07 & 2-Butene, (E) $\mathrm{C}_{4} \mathrm{H}_{8}$ \\
\hline 17 & 13.757 & 0,04 & $\mathrm{C}_{6} \mathrm{H}_{6}$ \\
\hline 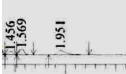 & $\approx x^{5}$ & & 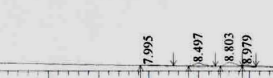 \\
\hline 2.0 & $\begin{array}{ll}3.0 & 4.0\end{array}$ & 5.0 & $\begin{array}{ll}8.0 & 9.0\end{array}$ \\
\hline
\end{tabular}

Figure 4. Detail of chromatograms of sample number 12/05. 
Table 2. Analysis of the composition of a sample number 17/06.

\begin{tabular}{|c|c|c|c|}
\hline $\begin{array}{l}\text { Number of the } \\
\text { peak }\end{array}$ & $\begin{array}{l}\text { Retention time, } \\
\text { minutes. мин }\end{array}$ & Peak area,\% & $\begin{array}{l}\text { The substance } \\
\text { (chemical formula) }\end{array}$ \\
\hline 1 & 1.266 & 37,26 & $\mathrm{~N}_{2}$ and $\mathrm{CO}$ in the sum \\
\hline 2 & 1.458 & 0,06 & $\mathrm{C}_{2} \mathrm{H}_{4}$ \\
\hline 3 & 1.567 & 2,74 & $\mathrm{C}_{2} \mathrm{H}_{6}$ \\
\hline 4 & 1.933 & 0,72 & $\mathrm{H}_{2} \mathrm{O}$ \\
\hline 5 & 3.216 & 45,16 & Propene $\mathrm{C}_{3} \mathrm{H}_{6}$ \\
\hline 6 & 5.210 & 0,16 & Dimethyl ether $\mathrm{C}_{2} \mathrm{H}_{4} \mathrm{O}$ \\
\hline 7 & 7.865 & 0,68 & Isobutane $\mathrm{C}_{4} \mathrm{H}_{10}$ \\
\hline 8 & 8.264 & 4,22 & 2-Butene $\quad \mathrm{C}_{4} \mathrm{H}_{8}$ \\
\hline 9 & 8.567 & 7,23 & Butane, $\mathrm{C}_{4} \mathrm{H}_{10}$ \\
\hline 10 & 8.764 & 1,21 & 2-Butene,(Z) $\mathrm{C}_{4} \mathrm{H}_{8}$ \\
\hline 11 & 9.117 & 0,07 & 2-Butene, (E) $\mathrm{C}_{4} \mathrm{H}_{8}$ \\
\hline
\end{tabular}

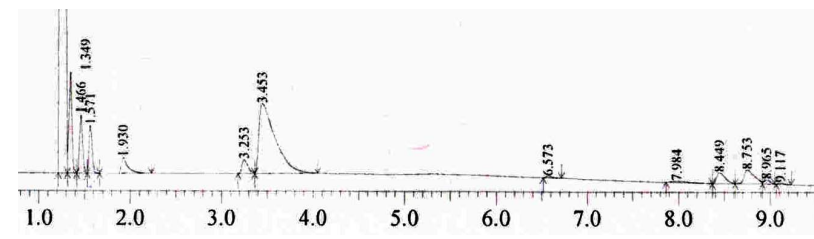

Figure 5. Detail of chromatograms of sample number 17/06.

\section{Acknowledgements}

The work is performed with the financial support of the grant from the Russian government No. 11.G34.31.0046 for public support of scientific research under the guidance of leading scholars in Russian universities (leading scientist - K.Hanyalich, NSU).and by the Ministry of Education and Science of the Russia, project No. 1.22.12.

\section{REFERENCES}

[1] Processing of synthesis gas: compact facility / / Analytical chemical industry portal. http://www.newchemistry.ru/.

[2] V. M. Batenin, L. S. Tolchinsky, J. L. Dolinsky, V. L. Tolchinsky. Modular units for processing of volatile hydrocarbon gases in methanol, high-octane gasoline, dimethyl ether and hydrogen // Energosintop LLC http://energosintop.boxmail.biz/.

[3] A. A. Nikiforov. The method of microarc oxidation // RF Patent No. 2389830 from 20.05.2010. 